\title{
ORIGIN OF THE MICROANGIOPATHIC CHANGES IN DIABETES
}

\author{
A. H. BARNETT \\ Birmingham
}

\begin{abstract}
SUMMARY
The mechanism of development of microangiopathy is incompletely understood, but relates to a number of ultrastructural, biochemical and haemostatic processes. These include capillary basement membrane thickening, non-enzymatic glycosylation, possibly increased free radical activity, increased flux through the polyol pathway and haemostatic abnormalities. The central feature appears to be hyperglycaemia, which is causally related to the above processes and culminates in tissue ischaemia. This article will briefly describe these processes and will discuss possible pathogenic interactions which may lead to the development of the pathological lesion.
\end{abstract}

Microangiopathy is a specific disorder of the small blood vessels which causes much morbidity and mortality in diabetic patients. Diabetic retinopathy is the commonest cause of blindness in the working population of the United Kingdom and diabetic nephropathy accounts for approximately $20 \%$ of deaths in diabetics below the age of 50 years. The major susceptibility factors for microangiopathy include disease duration, metabolic control and perhaps genetic factors and hypertension.

\section{THE MECHANISM OF DEVELOPMENT OF MICROANGIOPATHY}

\section{Capillary Basement Membrane Thickening (CBMT)}

The histological hallmark of microangiopathy ${ }^{1}$ is capillary basement membrane thickening (CBMT). The major structural element involved in CBMT is type IV collagen, and heparan sulphate is the major proteoglycan together with laminin and fibronectin. ${ }^{2-4}$ Heparan sulphate, produced by endothelial cells, is highly negatively charged and produces a regular lattice-work of anionic sites that hinders the filtration of negatively charged proteins such as albumin. In diabetes there appears to be impaired synthesis of proteoglycans and increase in hydroxylysine and

Correspondence to: Professor A. H. Barnett, Undergraduate Centre, East Birmingham Hospital, Bordesley Green East, Birmingham B9 5ST, UK. its glycosidally linked disaccharide units. Such alterations lead to abnormal packing of the peptide chains producing excessive leakiness of the membrane. The exact mechanisms of thickening and leakiness of basement membrane and their relevance to diabetic complications are not entirely clear, but appear to involve several biochemical mechanisms.

\section{Non-enzymatic Glycosylation}

In the presence of persistent hyperglycaemia glucose chemically attaches to proteins non-enzymatically to form a stable product (ketoamine or Amadori product) of which glycosylated haemoglobin is the best-known example. In long-lived tissue proteins such as collagen the ketoamine then undergoes a series of reactions resulting in the development of advanced glycosylation end products (AGE) (Fig. 1). ${ }^{5}$ AGE are resistant to degradation and continue to accumulate indefinitely on long-lived proteins. They are qualitatively identified by their characteristic brown pigment fluorescence ('protein browning') and participation in protein cross-linking. ${ }^{6}$ This could lead to trapping of albumin and immunoglobulin $\mathrm{G}$ within basement membrane. ${ }^{7}$ One study has reported a significant relationship between collagen browning and microangiopathy in skin biopsies from patients with insulin-dependent (type 1) diabetes mellitus, where AGE-corrected fluorescence was related to the severity of retinopathy, nephropathy and arterial and joint stiffness. ${ }^{8}$

\section{Protein Fluorescence, Free Radical Activity and Antioxidant Status}

Fluorescence of long-lived non-enzymatically glycosylated proteins may not be entirely due to glycosylation per $s e$. Free radicals, which are violently reactive chemical species having unpaired electron spins, will also induce oxidation of protein amino acid residues as well as lipid peroxidation. The former process leads directly to both protein cross-linking and fluorescence due to the formation of kynurenines from aromatic amino acid residues. ${ }^{9-11}$ In addition, non-enzymatic glycosylation of serum protein confers an increased susceptibility to free-radical-induced protein fluorescence and aggregation. ${ }^{12}$ 


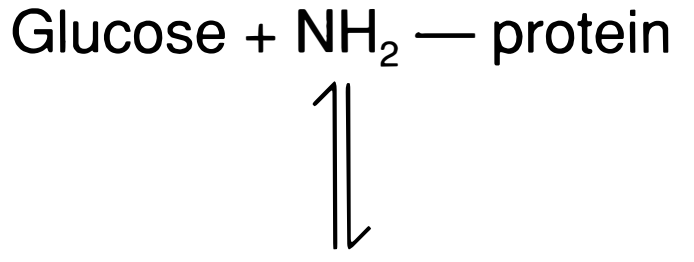

Schiff base (aldimine)<smiles>C=C=CC=CC</smiles>

\section{Amadori product} (ketoamine)

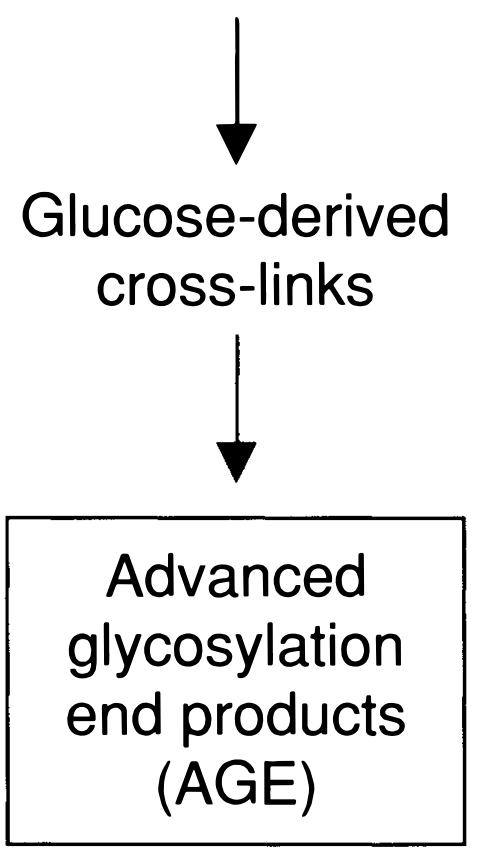

Fig. 1. The biochemical processes involved in non-enzymatic glycosylation of long-lived tissue proteins to form advanced glycosylation end products (AGE).

Increased free radical activity in diabetes is suggested from studies examining lipid peroxidation. There are reports of increased lipid peroxidation in diabetes particularly in relation to microangiopathy. ${ }^{13-15}$ Both free radicals

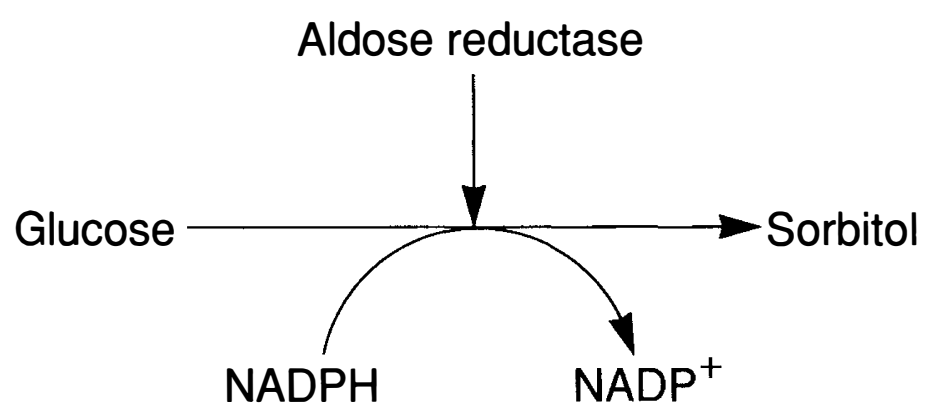

and their lipid hydroperoxide products may be directly cytotoxic to vascular endothelial cells. ${ }^{16}$ Apart from their direct cytotoxic effect, lipid hydroperoxides stimulate cyclooxygenase and hence prostaglandin synthesis while at the same time inhibiting prostacyclin production. ${ }^{16-18}$

Free radicals are produced continuously during many metabolic processes and are rapidly eliminated by antioxidants such as reduced glutathione (GSH) and vitamins $\mathrm{C}$ and E. Diabetic patients, however, have lower concentrations of GSH, ascorbate and vitamin E. ${ }^{19-22}$ The reduction in antioxidant reserve in diabetic patients may be due to competition for NADPH, which is a co-factor required to recycle the oxidised free radical scavengers back to the effective reduced form ('redox cycling'). NADPH is produced for the hexose monophosphate shunt and one source of competition from NADPH comes from the sorbitol pathway.

\section{Sorbitol (Polyol) Pathway}

The sorbitol or polyol pathway converts glucose to sorbitol and has been implicated in the pathogenesis of many diabetic complications (Fig. 2). ${ }^{23}$ In animal studies inhibition of aldose reductase has been shown to prevent microangiopathy ${ }^{24-26}$ although results in humans have been disappointing. ${ }^{27}$ The mechanism of action of aldose reductase inhibitors in these studies is unclear, but appears to be unrelated to the osmotic stress hypothesis of intracellular sorbitol accumulation. ${ }^{28}$ It is possible that increased flux through the polyol pathway causes increased NADPH utilisation resulting in less NADPH being available ${ }^{29}$ for conversion of antioxidants back to their free-radical-scavenging reduced form. This increased utilisation of NADPH may render the tissues less able to deal with oxidative stress.

\section{Protein Kinase C Activity}

Hyperglycaemia is associated with increased cellular protein kinase $C$ activity in cultured endothelial cells, resulting from enhanced synthesis of diacylglycerol from glucose.$^{30}$ Protein kinase $\mathrm{C}$ is involved in signal transduction of responses to hormones, growth factors and neurotransmitters. It can modify growth rate, DNA synthesis, hormone receptor turnover and contraction in vascular smooth muscle cells. It may have a role in the development of microangiopathy in relation to hyperglycaemia, but such a role needs detailed clarification.

\section{Sorbitol dehydrogenase}

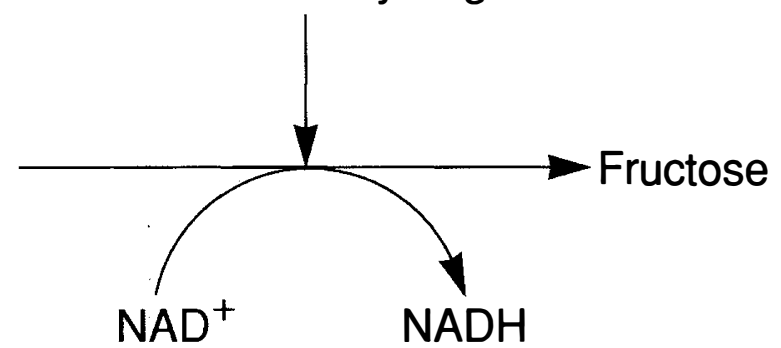

Fig. 2. The sorbitol (polyol) pathway. 


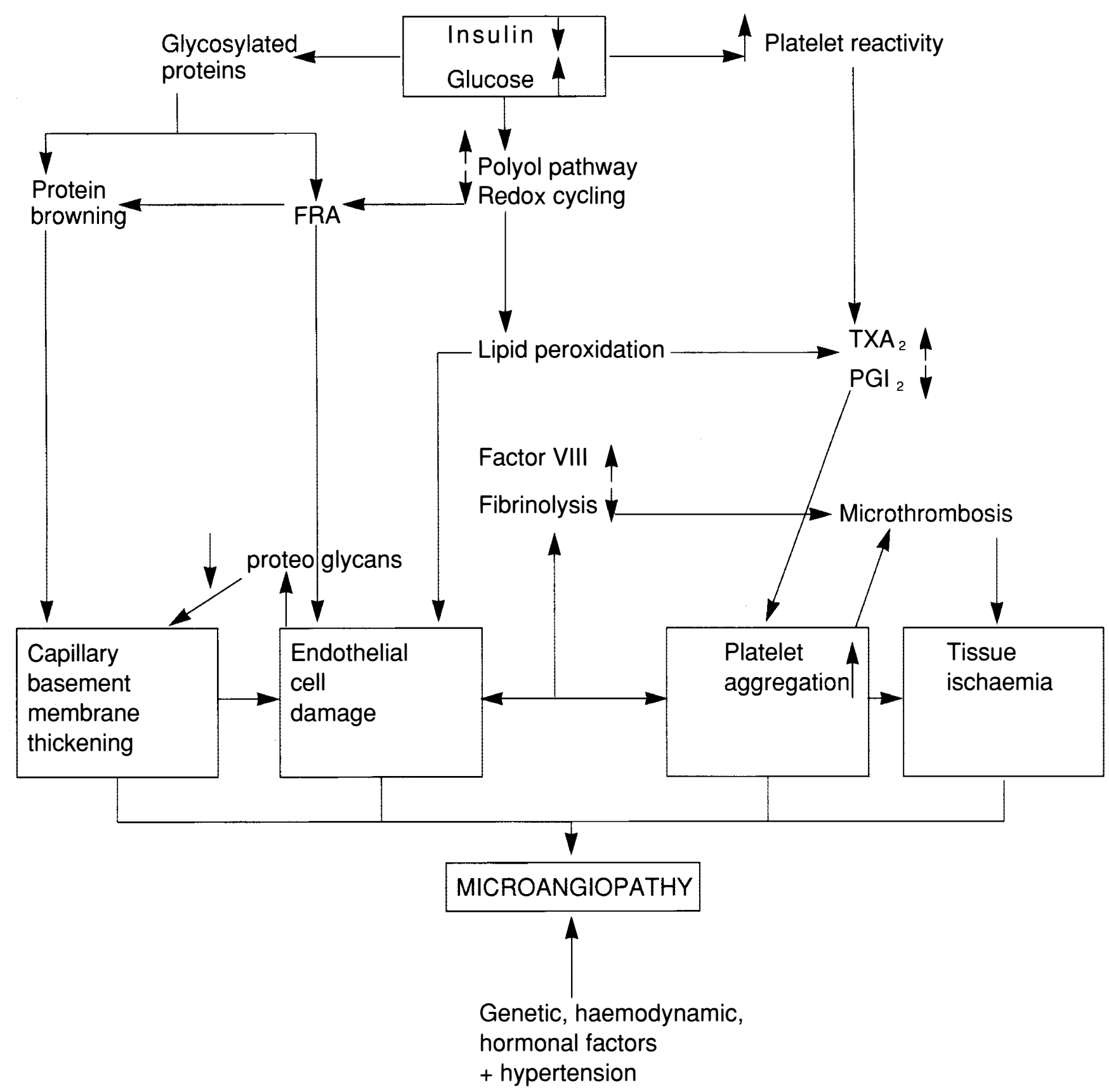

Fig. 3. Possible biochemical processes involved in the development of microangiopathy. FRA, free radical activity.

\section{Endothelial Cells and Abnormalities of}

\section{Haemostasis}

Factor VIII produced in the endothelial cell is increased in patients with early diabetic retinopathy, ${ }^{31}$ a situation which would promote microthrombus formation. Prostacyclin $\left(\mathrm{PGI}_{2}\right)$ is also produced in the endothelial cell and is a powerful vasodilator which antagonises platelet aggregation and platelet adherence to the vascular wall. Studies have shown decreased $\mathrm{PGI}_{2}$ production from vascular walls in animal models ${ }^{32}$ and reduced circulating $\mathrm{PGI}_{2}$ in diabetic patients. ${ }^{21}$ Plasminogen activator, which converts plasminogen to plasmin acting to promote fibrinolysis, has also been reported to be low in diabetes. ${ }^{33}$

The above abnormalities are mirrored by abnormalities in platelet function in diabetes. Thromboxane $A_{2}$ release is increased in platelets taken from patients with vascular complications $^{34,35}$ and this agent is a potential vasoconstrictor and causes platelet aggregation. The platelets also carry powerful mediators of the microcirculation such as serotonin and platelet derived growth factors. ${ }^{36,37}$ Increased platelet aggregation is well described in diabetics on the basis of measuring proteins released from the platelet on aggregation (e.g. $\beta$-thromboglobulin and platelet factor 4). ${ }^{38,39}$ Both techniques have detected increased platelet reactivity in diabetic microangiopathy.

The combination of reduced endothelial cell production of $\mathrm{PGI}_{2}$ and the activators of fibrinolysis, together with increased platelet reactivity and increased factor VIII production, produces a thrombotic tendency. This leads to microthrombus formation and small vessel occlusion and 
thus contributes to the abnormalities of blood flow in the small vessels.

\section{PATHOGENIC INTERACTIONS}

Possible pathogenic interactions are summarised in Fig. 3. The hypothesis suggests that hyperglycaemia is central, leading to excessive utilisation of NADPH via the polyol pathway and non-enzymatic glycosylation. Advanced glycosylation end products forming from long-lived tissue proteins, either spontaneously or from excess free radical formation, trap potentially damaging immunoglobulins and complement components. Excess free radicals may be produced either from protein glycation or because of inefficient elimination by reduced antioxidants, possibly secondary to NADPH utilisation and defective redox cycling. Endothelial cell dysfunction and damage, and increased platelet aggregation produced as a consequence of the above, further contribute to a vicious circle with release of factors such as $\mathrm{TXA}_{2}$ and factor VIII. The sequence culminates in CBMT, microthrombus formation and tissue ischaemia. These factors together with haemodynamic abnormalities, genetic susceptibility, hypertension and perhaps insulin-like growth factors result in the microvascular changes seen in susceptible target organs.

\section{CONCLUSIONS}

The mechanism of development of microangiopathy is likely to be complex, involving a number of different biochemical pathways. Increased knowledge of these pathways allows hypotheses to be constructed which can be tested. Further understanding of pathogenesis will suggest a number of therapeutic approaches which may lead in the future to important therapeutic options.

Key words: Basement membrane thickening, Free radicals, Glycosylation, Haemostasis, Microangiopathy, Polyol pathway, Prostaglandins.

\section{REFERENCES}

1. Spiro RG. Search for a biochemical basis of diabetic microangiopathy. Diabetologia 1976;12:1-14.

2. Beisswenger PJ, Spiro RG. Studies on the human glomerular basement membrane: composition, nature of the carbohydrate units and chemical changes in diabetes mellitus. Diabetes 1973;22:180-93.

3. Kefalides NA. Biochemical properties of human glomerular basement membrane in normal and diabetic kidneys. J Clin Invest 1974;53:403-7.

4. Kanwar YS, Hascall VC, Farquhar MG. Partial characterisation of newly synthesised proteoglycans isolated from the glomerular basement membrane. J Cell Biol 1981;90: 527-32.

5. Uitto J, Perejda A, Grant GA, Rowold E, Kilo CA, Williamson JR. Glycosylation of human glomerular basement membrane collagen: increased content of hexose in ketoamine linkage and unaltered hydroxylysine-o-glycosides in patients with diabetes. Connect Tissue Res 1982;10:287-96.

6. Reynolds TM. Chemistry of non-enzymatic browning. Adv Food Res 1965;14:167-283.

7. Brownlee M, Pongor S, Cerami A. Covalent attachment of soluble proteins by non-enzymatically glycosylated collagen: role of in situ formation of immune complexes. J Exp Med 1983;158:1739-44.
8. Monnier VM, Vishwanath V, Frank KE, Elmets GA, Dauchot P, Khon RR. Relation between complications of type 1 diabetes mellitus and collagen-linked fluorescence. $\mathbf{N ~ E n g l ~ J ~}$ Med 1986;314:403-8.

9. Wickens DG, Norden AG, Lunec J, Dormandy TL. Fluorescence changes in human gamma-globulin induced by free radical activity. Biochim Biophys Acta 1983;742: 607-16.

10. Wickens DG, Gaff TL, Lunec J, Dormandy TL. Free radical mediated aggregation of human gamma globulin. Agents Actions 1981;11:6-7.

11. Jennings PE, Barnett AH. New approaches to the pathogenesis and treatment of diabetic microangiopathy. Diabetic Med 1987;5:111-7.

12. Jones AF, Jennings PE, Wakefield A, Winkles JW, Lunec J, Barnett AH. Protein browning and diabetic complications. Lancet 1986;2:459.

13. Nishigaki I, Hagihara M, Tsunekawa H, Maseki M, Yagi K. Lipid peroxide levels of serum lipoprotein fractions of diabetic patients. Biochem Med 1981;25:373-8.

14. Kaji H, Kurasaki M, Ito K, et al. Increased lipoperoxide value and glutathione peroxidase activity in blood plasma of type II (non-insulin dependent) diabetic women. Klin Wochenschr 1985;63:765-8.

15. Jennings PE, Jones AF, Florkowski CM, Lunec J, Barnett $\mathrm{AH}$. Increased diene conjugates in diabetic subjects with microangiopathy. Diabetic Med 1987;4:452-6.

16. Hemler ME, Cook HW, Lands WEM. Prostaglandin biosynthesis can be triggered by lipid peroxides. Arch Biochem Biophys 1979; 193:340-5.

17. Warso MA, Lands WEM. Lipid peroxidation in relation to prostacyclin and thromboxane physiology and pathophysiology. Br Med Bull 1983;39:277-80.

18. Ham EG, Egan RW, Soderman DD, Gale PH, Kuehl FA. Peroxidase dependent deactivation of prostacyclin synthetase. J Biol Chem 1979;254:2191-4.

19. Chari SW, Nath N, Rathi AB. Glutathione and its redox system in diabetic polymorphonuclear leucocytes. Am J Med Sci 1984;287:14-5.

20. Stankova L, Riddle M, Larned J, et al. Plasma ascorbate concentrations and blood cell dehydroascorbate transport in patients with diabetes mellitus. Metabolism 1984;33: 347-53.

21. Jennings PE, Chirico S, Jones AF, Lunec J, Barnett AH. Vitamin $C$ metabolites and microangiopathy in diabetes mellitus. Diabetes Res 1987;6:151-4.

22. Sinclair AJ, Girling AJ, Gray L, Le Guen C, Lunec J, Barnett AH. Disturbed handling of ascorbic acid in diabetic patients with and without microangiopathy during high dose ascorbate supplementation. Diabetologia 1991;34:171-5.

23. Cogan DG. Aldose reductase and complications of diabetes. Ann Intern Med 1984;101:82-91.

24. Robinson WG, Kador PF, Kinoshita JH. Early retinal microangiopathy: prevention with aldose reductase inhibitors. Diabetic Med 1985;2:196-9.

25. Cohen M. Aldose reductase inhibition, glomerular metabolism and diabetic nephropathy. Diabetic Med 1985;2: 203-6.

26. Jedziniak JA, Chylack LT, Cheng M-H, et al. The sorbitol pathway in the human lens: aldose reductase and polyol dehydrogenase. Invest Ophthalmol 1981;20:314-26.

27. Florkowski CM, Rowe BR, Nightingale S, Harvey TC, Barnett AH. Clinical and neurophysiological studies of aldose reductase inhibitor Ponalrestat in chronic symptomatic diabetic peripheral neuropathy. Diabetes 1991;40: 129-33.

28. Gonzalez AM, Sochor M, McLean P. The effect of an aldose reductase inhibitor (Sorbinil) on the level of metabolites in the lenses of diabetic rats. Diabetes 1984;32:482-5.

29. Barnett PA, Gonzalez RG, Chylack LT, Chen H-M. The 
effect of oxidation on sorbitol pathway kinetics. Diabetes 1986;35:426-32.

30. Lee T-S, Saltsman A, Ohaski H, King GL. Activation of protein kinase $\mathrm{C}$ by elevation of glucose concentrations: proposal for a mechanism in the development of diabetic vascular complications. Proc Natl Acad Sci USA 1989;86: 5141-5.

31. Porta M, Townsend C, Clover GM, et al. Evidence for functional endothelial cell damage in early diabetic retinopathy. Diabetologia 1981;20:597-601.

32. Carreras LO, Chamone DAF, Klerckx P, Vermylen J. Decreased vascular prostacyclin $\left(\mathrm{PGI}_{2}\right)$ in diabetic rats: stimulation of $\mathrm{PGI}_{2}$ release in normal and diabetic rats by the antithrombotic compound BAYg 6575. Thromb Res 1980; 19:663-70.

33. Hassen KF, Dahl-Jorgensen K, Lauritzen T, Feldt-Rasmussen B, Brinchmann-Hansen O, Deckert T. Diabetic control and microvascular complications: the near-normoglycaemic experience. Diabetologia 1986;29:677-84.

34. Ziboh VA, Maruta H, Lord J, Cagle WD, Lucky W.
Increased biosynthesis of thromboxane $\mathrm{A}_{2}$ by diabetic platelets. Eur J Clin Invest 1979;9:223-8.

35. Butkus A, Shiney EK, Schumacher OP. Thromboxane biosynthesis in platelets of diabetic and coronary artery diseased patients. Artery 1982;11:238-51.

36. Chmielewski J, Farbiszewski R. Platelet factor 4 release during human platelet aggregation in diabetic patients. Thromb Haemost 1970;24:203-5.

37. Sacchni S, Curci G, Piccinin L, et al. Platelet alpha granule release in diabetes mellitus. Scand J Clin Lab Invest 1985; 45:165-8.

38. Paulsen EP, McChung NM, Sabio H. Some characteristics of spontaneous platelet aggregation in young insulin dependent diabetic subjects. Horm Metab Res 1981; Suppl 11:15-21.

39. Dallinger KJC, Jennings PE, Toop MJ, Gyde OHB, Barnett $\mathrm{AH}$. Platelet aggregation and coagulation factors in insulin dependent diabetics with and without microangiopathy. Diabetic Med 1987;4:44-8. 